\title{
População de Metarhizium anisopliae em diferentes tipos e graus de compactação do solo
}

\author{
Metarhizium anisopliae population in differents soil types and compactness degrees
}

\section{Lourenço Maurício Lanza ${ }^{1}$ Antonio Carlos Monteiro ${ }^{2}$ Euclides Braga Malheiros ${ }^{3}$}

\section{RESUMO}

Este trabalho objetivou investigar a influência do tipo e compactação do solo na sobrevivência do fungo Metarhizium anisopliae. A sobrevivência do fungo foi determinada em quatro tipos de solos: Latossolo Vermelho textura argilosa, Latossolo Vermelho textura média, Argissolo Vermelho Amarelo textura arenosa média e Argissolo Vermelho Amarelo textura areno-argilosa, com maior teor de matéria orgânica. Para determinar o efeito da compactação na sobrevivência do fungo usaram-se os três primeiros tipos de solos nas densidades de 1,12, 1,32, 1,50 $\mathrm{cm}^{-3} ; 1,22,1,44$, $1,65 \mathrm{~g} \mathrm{~cm}^{-3} ; 1,30,1,50,1,70 \mathrm{~g} \mathrm{~cm}^{-3}$, respectivamente. Por meio da contagem de unidades formadoras de colonias (UFC) em placas de Petri, fizeram-se avaliações da sobrevivência do fungo, após zero, 20, 40, 60, 80, 100 e 120 dias de incubação a $27 \pm 1^{\circ} \mathrm{C}$. Houve influência significativa do tipo de solo e do grau de compactação na sobrevivencia do fungo, obtendose maior quantidade de UFC no solo textura areno-argilosa. Entre os demais solos, a maior sobrevivência ocorreu no solo textura arenosa e a menor no solo textura argilosa. $O$ efeito da compactação foi significativo para o tipo de solo, exceto no solo textura arenosa. Independentemente do tipo de solo, a maior sobrevivência foi observada nos valores médios de densidade. A compactação teve maior impacto no solo textura média, onde ocorreu queda mais acentuada na quantidade de UFC em todas as densidades.

Palavras-chave: controle biológico, controle microbiano, ecologia, fungo entomopatogênico.

\section{ABSTRACT}

The aim of this work was to investigate the effect of different soil types and compactness on Metarhizium anisopliae survival. The fungus survivorship was determined in four soil types: Red Latosol with clay texture, Red Latosol with medium texture, Red Yellow Podzolic with medium sand texture and Red Yellow Podzolic with sand-clay texture, with higher amount of organic material. To determine the effect of compactness on fungus survival the first three soil types were used with the following densities, respectively: 1.12, 1.32, $1.50 \mathrm{~g} \mathrm{~cm}^{-3} ; 1.22,1.44,1.65 \mathrm{~g} \mathrm{~cm}^{-3} ; 1.30,1.50,1.70 \mathrm{~g} \mathrm{~cm}^{-3}$ The fungus survivorship was evaluated at zero, 20, 40, 60, $80,100,120$ days of incubation at $27 \pm 1^{\circ} \mathrm{C}$, through colony forming units (CFU), in Petri dishes. There was significant effect of the soil type and compactness on the survival of the fungus. Survival was greater in the soil with sand-clay texture and high number of $C F U$ was observed in sandy soil compared with medium texture and clay soil. A significant effect of compactness was verified for the soil type, but not for the medium sand texture soil. Despite the soil type, the fungus survivorship was greater when the soil compactness was at the medium density values. The effect of compactness was most effective in the medium texture soil, in which the fungus survival was lower in all densities.

Key words: biological control, ecology, entomopathogenic fungus, microbial control.

\section{INTRODUÇÃO}

Os fungos entomopatogênicos exercem a função de controle de insetos em ambientes naturais e ecossistemas agrícolas, ocupando um lugar relevante na manutenção do equilíbrio ecológico. Nos últimos anos, o seu uso vem se intensificando, com vantagens em muitas situações, em substituição aos produtos químicos (PEREIRA et al.,1998). Estudos ecológicos envolvendo estes agentes de controle focalizam-se em dois aspectos: o primeiro são os fatores ambientais e biológicos que afetam a interação inseto-hospedeiro, e o segundo refere-se à persistência e estabilidade dos patógenos após a introdução em um ecossistema. Ambos os tipos de estudos têm envolvido trabalhos realizados em laboratório e campo para investigar a influência do tipo de solo, umidade, temperatura, luz, competição e produtos químicos (RATH et al., 1992).

${ }^{1}$ Biólogo, Mestre, Ex-aluno do Programa de Pós-graduação em Microbiologia, Faculdade de Ciências Agrárias e Veterinárias (FCAV), Universidade Estadual Paulista (UNESP). E-mail: lmlanza@netsite.com.br.

${ }^{2}$ Biólogo, Doutor, FCAV, UNESP, Via de Acesso Professor Paulo Donato Castellane, s/n. 14884-900, Jaboticabal, SP. E-mail: montecar@fcav.unesp.br. Autor correspondente.

${ }^{3}$ Matemático, Livre-Docente, FCAV, UNESP. E-mail: euclides@fcav.unesp.br 
O solo é o reservatório natural de fungos que infectam insetos. Estes fungos têm sua estabilidade influenciada tanto por fatores bióticos como abióticos do ambiente. A fungistase é apontada como um importante fator limitante da sobrevivência e a microbiota do solo tem sido relatada por vários autores como um dos principais agentes que afetam a sobrevivência dos fungos (LINGG \& DONALDSON, 1981; SHIELDS et al., 1981; SHARAPOV \& KALVISH, 1984; GRODEN \& LOCKWOOD, 1991).

A sobrevivência do fungo depende primariamente da temperatura e conteúdo de água. A temperatura ideal do solo para a persistência de fungos entomopatogênicos varia amplamente de acordo com a linhagem do fungo, tipo de solo, umidade e antagonistas. Temperaturas baixas ou medianas e valores intermediários de saturação do solo favorecem a sobrevivência dos conídios (LINGG \& DONALDSON, 1981), enquanto altas temperaturas e teores de saturação elevados reduzem a sobrevivência (STUDDERT \& KAYA, 1990).

Os solos são classificados de acordo com atributos morfológicos, físicos, químicos e mineralógicos (PRADO, 2001). Fatores como tipo de solo, grau de compactação, $\mathrm{pH}$, textura, etc, podem exercer efeito significativo na sobrevivência dos conídios. O ambiente do solo pode ser visto como um ecossistema extremamente complexo envolvendo e interferindo com as interações primárias entre insetos hospedeiros e patógenos fúngicos, ou pode ser visto como um ecossistema simples e estável que abriga a interação patógeno-hospedeiro (RATH, 2002).

Raízes de plantas e microrganismos vivem em poros em solo contendo água e gases (RATH, 2002). Solos bem estruturados, com agregados estáveis e poros com tamanhos diversos são requeridos para uma boa atividade microbiana, retenção de água e penetração das raízes (MOREIRA \& SIQUEIRA, 2002). Alterações na estrutura do solo podem tornar o ambiente menos favorável para a atividade biológica de microrganismos. Segundo GROHMANN (1972), camadas compactadas e adensadas constituem um impedimento físico ao desenvolvimento do sistema radicular e restrição ao movimento da água e do ar ao longo do perfil do solo.

Os fatores que podem atuar nas populações de fungos entomopatogênicos no solo necessitam ser melhor conhecidos. O presente trabalho objetivou estudar a influência do tipo e do grau de compactação do solo na sobrevivência do fungo Metarhizium anisopliae.

\section{MATERIAL E MÉTODOS}

Utilizou-se o isolado E9 de Metarhizium anisopliae, obtido de Deois flavopicta (cigarrinhadas-pastagens) e mantido em cultura estoque a $4^{\circ} \mathrm{C}$, em tubo de ensaio contendo meio de batata-dextroseagar (BDA) inclinado. O isolado foi cultivado em placas de Petri com BDA e mantido em BOD a $27 \pm 0,5^{\circ} \mathrm{C}$, por 15 dias. As suspensões de conídios foram padronizadas em $2,0 \times 10^{7}$ conídios $\mathrm{mL}^{-1}$ e preparadas por transferência de esporos da superfície de colônias rejuvenescidas para tubos contendo uma mistura (1:1) de solução salina de $\mathrm{NaCl}$ a $0,89 \%$ (p/v) e solução de Tween $80^{\circledR}$ a $0,1 \%$ (v/v). A contagem de conídios foi feita em câmara de Neubauer.

Os solos foram coletados entre janeiro e abril de 2002, na profundidade de 0 a $20 \mathrm{~cm}$, em matas de preservação ambiental, existentes em propriedades agrícolas do município de Jaboticabal ou próximo deste. Depois de secos em temperatura ambiente, foram destorroados, peneirados em malha de $1 \mathrm{~mm}$ e armazenados em sacos de plástico até a utilização. A análise de suas características físicas e químicas foi realizada no laboratório do Departamento de Solos e Adubos da Faculdade de Ciências Agrárias e Veterinárias da Universidade Estadual Paulista, Jaboticabal, SP. A capacidade de saturação de cada tipo de solo foi determinada antes de cada ensaio.

Os ensaios foram sempre realizados com cinco placas de Petri (repetições) por tratamento, contendo, cada placa, $80 \mathrm{~g}$ de solo. Dois palitos de madeira foram fixados, com fita adesiva, em toda a extensão da face interna da tampa da placa para facilitar as trocas gasosas. Após pesadas, as placas foram envoltas em conjunto de três com dupla folha de papel e autoclavadas a $121^{\circ} \mathrm{C}$ e $1 \mathrm{Kgf} \mathrm{cm}^{-2}$ durante $60 \mathrm{~min}$. Após a autoclavagem, o papel foi trocado quando necessário.

Depois de autoclavados, os solos receberam, em ambiente asséptico, água destilada esterilizada em quantidade suficiente para atingir $65 \%$ de saturação. Após repouso por 3h para estabilização, o solo foi inoculado com $2 \mathrm{~mL}$ de uma suspensão de 2,0 x $10^{7}$ con. $\mathrm{mL}^{-1}$, distribuída por toda a superfície do mesmo.

Durante os ensaios, os solos permaneceram a $27 \pm 1^{\circ} \mathrm{C}$, no escuro. Recipientes com água foram colocados no interior da estufa, para manter o ambiente úmido. Semanalmente, as placas foram pesadas e, considerando o peso inicial acrescido do peso da água usada para umidecimento e a contida no inóculo, a água perdida foi reposta.

As avaliações da sobrevivência do fungo foram realizadas nos tempos $0,20,40,60,80,100$ e 120 
dias de incubação. Em cada avaliação, uma amostra de $1,0 \mathrm{~g}$ de solo úmido, composta de 15 a 20 sub-amostras colhidas na superfície de cada placa foi suspendida em $9 \mathrm{~mL}$ de solução aquosa de Tween $80^{\circledast}$ a $0,1 \%$ (v/v). A partir desta suspensão inicial, fizeram-se diluições seriadas, adequando-se o título das diluições decimais em cada avaliação, de acordo com a perspectiva de aumento ou redução da quantidade de UFC (Unidades Formadoras de Colônias) no solo, em função do tempo de incubação. Em seguida, semeou-se $0,1 \mathrm{~mL}$ da suspensão em placas de Petri contendo $20 \mathrm{~mL}$ do meio de cultura de JOUSSIER \& CATROUX (1976), modificado pela supressão do suco de vegetais e oxgall. Para cada amostra de solo, foram semeadas três placas de Petri das diluições com maior expectativa de obter a quantidade de 30 a 300 UFC por placa de Petri. As placas foram mantidas em estufa a $27 \pm 1^{\circ} \mathrm{C}$, no escuro, e o número de UFC, em cada placa, foi determinado até o $5^{\circ}$ dia de incubação.

No ensaio conduzido para avaliar o efeito do tipo de solo, utilizaram-se: Latossolo Vermelho textura argilosa [53\% de argila, $18 \%$ de silte, $29 \%$ de areia e 3,5\% de matéria orgânica (M O)]), coletado em propriedade agrícola no Distrito de Lusitânia, Município de Jaboticabal, SP (21 $07^{\circ} 04^{\prime \prime} \mathrm{S}$; $48^{\circ} 16^{\prime} 44^{\prime \prime}$ $\mathrm{W})$; Latossolo Vermelho textura média (27\% de argila, $9 \%$ de silte, $64 \%$ de areia e $2 \%$ de M O), coletado próximo ao cruzamento das rodovias SP 326 e SP 333, Município de Jaboticabal, SP $\left(21^{\circ} 17^{\prime} 00^{\prime \prime} \mathrm{S}\right.$; $48^{\circ} 20^{\prime} 00^{\prime \prime}$ $\mathrm{W})$; Argissolo Vermelho Amarelo textura arenosa média ( $15 \%$ de argila, $7 \%$ de silte, $78 \%$ de areia e $2,6 \%$ de $\mathrm{M} \mathrm{O})$, coletado em propriedade agrícola do Município de Monte Alto, SP (21 $1^{\circ} 21^{\prime} 02^{\prime \prime} \mathrm{S} ; 48^{\circ} 31^{\prime} 17^{\prime \prime}$ W) e um Argissolo Vermelho Amarelo textura arenoargilosa (com maior teor de matéria orgânica) (12\% de argila, $17 \%$ de silte, $68 \%$ de areia e $4,9 \%$ de $\mathrm{M} \mathrm{O}$ ), coletado no Horto Florestal Guarani, Município de Pradópolis, SP (21 26 $\left.02^{\prime \prime} \mathrm{S} ; 48^{\circ} 05^{\prime} 21^{\prime \prime} \mathrm{W}\right)$.

No ensaio destinado à avaliação do efeito da compactação, utilizaram-se os solos de textura argilosa, média e arenosa média e três graus de compactação (baixa, média e alta), obtidos por diferentes densidades. A menor densidade foi determinada pela relação entre a massa do solo sem compactação e o volume ocupado na placa; a maior densidade foi obtida pela máxima compactação do solo obtida nas placas, nas condições do ensaio, e o volume ocupado depois da compactação; a densidade média foi determinada pela média entre a maior e a menor densidade.

Os solos foram compactados, nas placas, com o auxílio de um soquete e martelo, sendo adicionada água destilada antes da compactação, em quantidade suficiente para atingir $65 \%$ de saturação. Para cada tipo de solo, as densidades obtidas foram: $1,12,1,32$ e $1,50 \mathrm{~g} \mathrm{~cm}^{-3} ; 1,22,1,44 \mathrm{e} 1,65 \mathrm{~g} \mathrm{~cm}^{-3} ; 1,30,1,50$ e $1,70 \mathrm{~g} \mathrm{~cm}^{-3}$ para os solos de textura argilosa, média e arenosa média, respectivamente.

Após autoclavagem, as placas foram pesadas e a quantidade de água perdida foi reposta com água esterilizada, considerando-se ainda a necessidade de adição de $2 \mathrm{~mL}$ de inóculo.

Os ensaios foram organizados segundo o delineamento inteiramente casualisado (DIC). A análise foi realizada através do teste $\mathrm{F}$ e as médias foram comparadas pelo teste de Tukey a 5\% de probabilidade de erro. Para a execução das análises utilizou-se o procedimento GLM do programa SAS, versão 6.12-2003.

\section{RESULTADOS}

Influência do tipo de solo

O tipo de solo influenciou significativamente a sobrevivência do fungo. Verificou-se também influência significativa $(\mathrm{p}<0,01)$ do tempo de incubação, inclusive em relação aos tipos de solo. $\mathrm{O}$ solo de textura areno-argilosa foi o que propiciou maior sobrevivência do fungo, seguido do solo de textura arenosa média. A menor quantidade de UFC foi verificada nos solos de textura argilosa e textura média. A população do fungo aumentou nos solos de textura areno-argilosa, arenosa média e de textura média, até 40 dias após a inoculação; em seguida, verificou-se uma redução na quantidade de UFC obtidas, indicando um declínio na sobrevivência até o $120^{\circ}$ dia de incubação. Exceção a isso, observou-se no solo de textura argilosa, cujo aumento da população, mais lento, ocorreu até o $80^{\circ}$ dia de incubação, a partir do qual também se observou um decréscimo na sobrevivência do fungo (Figura 1).

\section{Efeito da compactação}

A sobrevivência do fungo foi influenciada $(\mathrm{p}<0,01)$ pela interação entre o tipo e densidade do solo e o tempo de incubação, indicando que o grau de compactação pode ter papel importante na manutenção do fungo no solo.

Independentemente do tipo de solo, o fungo apresentou maior sobrevivência no grau de compactação caracterizado por valores médios de densidade. O fungo cresceu, nos três tipos de solo até o $20^{\circ}$ dia de incubação; em seguida ocorreu uma redução na quantidade de UFC obtidas indicando queda na sobrevivência até o $120^{\circ}$ dia de incubação (Figura 2 A, B e C). Exceção a esta tendência foi observada no crescimento do fungo na densidade de 


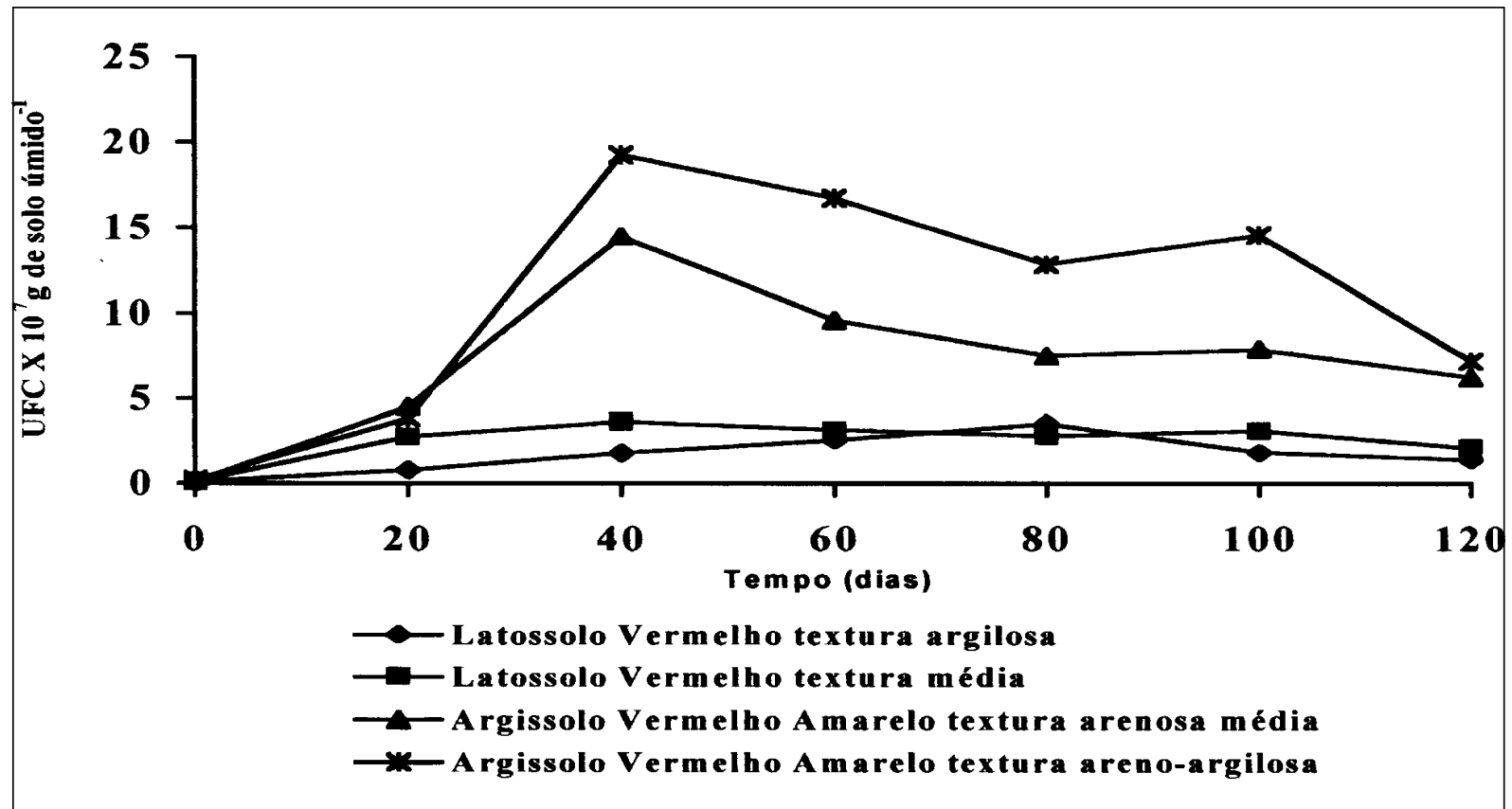

Figura 1 - Efeito do tipo de solo na sobrevivência de Metarhizium anisopliae em função do tempo. Figura construída com valores não convertidos em logarítmo.

$1,50 \mathrm{~g} \mathrm{~cm}^{-3}$ no solo argiloso, que se manteve até o $80^{\circ}$ dia. Neste solo a sobrevivência do fungo, nas densidades de 1,12 e $1,32 \mathrm{~g} \mathrm{~cm}^{-3}$, foi semelhante até o $60^{\circ}$ dia de incubação, mas a partir do $80^{\circ}$ dia, a densidade de $1,32 \mathrm{gcm}^{-3}$ proporcionou melhores condições para a sobrevivência do fungo (Figura 2A).

O impacto da compactação foi mais acentuado no solo textura média, onde se observou queda mais acentuada na sobrevivência do fungo em todas as densidades. Neste solo, não houve diferenças acentuadas que pudessem ser atribuídas ao fator compactação, contudo a maior sobrevivência ocorreu na densidade média $\left(1,44 \mathrm{~g} \mathrm{~cm}^{-3}\right)$ (Figura 2B).

\section{DISCUSSÃO}

Após a inoculação de $\boldsymbol{M}$. anisopliae nos solos autoclavados, o crescimento saprofítico do fungo foi rápido em todos os tipos de solo, provavelmente com grande produção de conídios, pela ausência de competidores e fácil utilização dos nutrientes minerais e matéria orgânica disponível. Contudo, este crescimento não ocorreu de forma homogênea evidenciando a influência dos tipos de solo avaliados.

Os maiores crescimentos foram observados no solo de textura areno-argilosa com maior teor de matéria orgânica $(4,9 \%)$ e no solo de textura arenosa média, mas com conteúdo de matéria orgânica relativamente baixo $(2,6 \%)$. Devido ao fato de os solos arenosos conterem proporcionalmente grande quantidade de poros médios e grandes (OLIVEIRA, 2001), possivelmente isso facilitou o crescimento hifálico, permitindo exploração mais efetiva dos recursos nutricionais e melhor troca gasosa, o que contribuiu para o crescimento do fungo. No solo de textura areno-argilosa, o teor de matéria orgânica foi, provavelmente, fator significativo para suportar o crescimento. OLIVEIRA et al. (1981) relataram um aumento gradual de propágulos de $\boldsymbol{M}$. anisopliae em solo esterilizado, embora tenha ocorrido uma sensível redução populacional nos primeiros 15 dias após a inoculação; os autores atribuíram esta redução ao período de adaptação do fungo ao substrato, mas este efeito não foi observado em nossos ensaios.

No solo de textura argilosa, o crescimento ocorreu de forma mais lenta; a presença de maior teor de argila reduz a porosidade e aumenta a retenção de água, dificultando a aeração e extensão hifálica, e por consequiência, a exploração nutricional do solo. CORREA \& AZEVEDO (1986) verificaram que solos argilosos são menos eficazes que solos arenosos em manter a viabilidade de conídios M. anisopliae. Segundo RATH et al. (1992), o isolamento de M. anisopliae de solo 


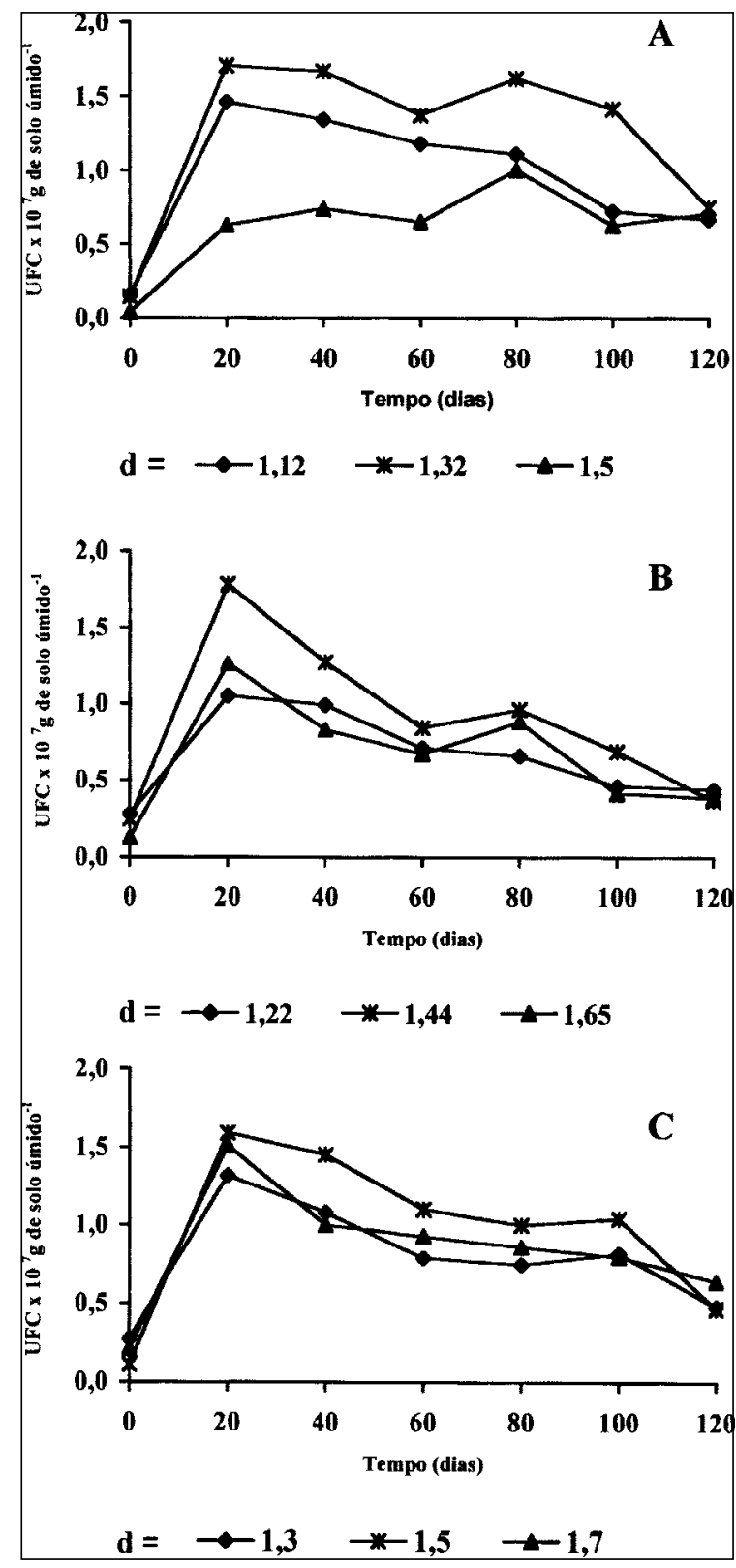

Figura 2 - Efeito da densidade $\left(\mathrm{d}=\mathrm{g} \mathrm{cm}^{-3}\right)$ na sobrevivência de Metarhizium anisopliae em três tipos de solo e três graus de compactação. A: Latossolo Vermelho textura argilosa; B: Latossolo Vermelho textura média; C: Argissolo Vermelho Amarelo textura arenosa média. Figura construída com valores não convertidos em logarítmo.

argiloso foi mais freqüente do que de outros tipos de solo. Contudo, entre as quatro linhagens mais comumente isoladas, apenas uma mostrou preferência por tipo de solo, sendo mais isolada de solo argiloso.

Após ter colonizado o solo e provavelmente esgotado as reservas nutricionais, observou-se progressiva redução na sobrevivência do fungo. Entretanto, esta redução ocorreu de modo similar em todos os tipos de solos, não podendo ser atribuída a nenhum fator edáfico específico. Segundo BIDOCHKA et al. (1998), há uma multiplicidade de fatores que podem influenciar a sobrevivência de fungos entomopatogênicos no solo mas, em geral, $\boldsymbol{M}$. anisopliae pode persistir neste ambiente por longos períodos.

Os resultados obtidos neste trabalho indicam que a compactação do solo influenciou no desempenho de $\boldsymbol{M}$. anisopliae, cujo crescimento e sobrevivência foram favorecidos por valores intermediários de densidade em todos os tipos de solo.

A compactação, expressa por valores crescentes de densidade, altera a estrutura do solo, reduzindo o tamanho e abertura dos poros. Como conseqüência, restringem-se as trocas gasosas, com a possibilidade de formação de bolsões anaeróbios (LYNCH, 1986), o conteúdo e disponibilidade de água, a circulação da solução do solo que disponibiliza nutrientes, e até mesmo os espaços disponíveis para o crescimento fúngico.

Nas densidades médias, provavelmente atingiu-se um equilíbrio na quantidade e tamanho dos poros, permitindo otimizar as condições para crescimento e sobrevivência do fungo. SOSA-GOMEZ \& MOSCARDI (1994) encontraram maior prevalência de Beauveria bassiana, M. anisopliae e Paecilomyces spp em solo não submetido à aração, quando comparado a solo arado. Nas maiores densidades, a possível redução na porosidade do solo estabeleceu condições limitantes, como por exemplo, redução da aeração e obstrução mecânica pela diminuição dos espaços disponíveis para o crescimento. CALLOT et al. (1996) relataram que Beauveria brongniartii coloniza o solo através de estruturas hifálicas (hyphasmata) semelhantes a rizomorfas que se desenvolvem através de canais e lacunas existentes no solo, principalmente quando o solo está compactado. Quando o solo está mais fragmentado, o micélio se expande por meio de finos segmentos hifálicos. Nas menores densidades, o aumento da porosidade, facilitando a perda de água, pode ter dificultado a mobilidade de nutrientes, reduzindo sua disponibilidade para o fungo.

$\mathrm{O}$ efeito da compactação foi significativo para os tipos de solo, exceto para o solo de textura arenosa média. No solo de textura argilosa e de textura média, possivelmente o melhor equilíbrio nas proporções de argila e areia promoveu rearranjos estruturais diferenciados em função das diferentes densidades, mas isso não ocorreu no solo de textura 
arenosa média onde a quantidade de areia grossa é substancialmente maior do que a de argila.

\section{CONCLUSÕES}

A sobrevivência de $\boldsymbol{M}$. anisopliae é influenciada pelo tipo e grau de compactação do solo, sendo favorecida pelo solo com textura areno-argilosa, com maior teor de matéria orgânica e é maior em solo pouco compactado.

\section{AGRADECIMENTOS}

Os autores agradecem ao Prof. Dr. José Frederico Centurion do Departamento de Solos e Adubos da Faculdade de Ciências Agrárias e Veterinárias, Unesp, Jaboticabal, SP, pela assistência técnica nas análises e classificação dos solos.

\section{REFERÊNCIAS BIBLIOGRÁFICAS}

BIDOCHKA, M.J. et al. Occurrence of the entomopathogenic fungi Metarhizium anisopliae and Beauveria bassiana in soils from temperate near-northen habitats. Canadian Journal of Botany, v.76, n.7, p.11981204, 1998.

CALLOT, G. et al. Hyphasmata and conidial pellets: an original morphologycal aspect of soil colonization by Beauveria brongniartii. Journal of Invertebrate Pathology, v. 68 , n.2, p.173-176, 1996.

CORRÊA, G.S.; AZEVEDO, J.L. Efeito do solo na germinação de conídios de Metarhizium anisopliae (Metsch.) Sorokin. O Solo, v.78, n.1, p.39-41, 1986.

GRODEN, E.; LOCKWOOD, J.L. Effects of soil fungistasis on Beauveria bassiana and its relationship to disease incidence of the colorado potato beetle, Leptinotarsa decemlineata, in Michigan and Rhode Island soils. Journal of Invertebrate Pathology, v.57, n.1, p.7-16, 1991.

GROHMANN, F. Compacidade. In: MONIZ, A.C. Elementos de pedologia. São Paulo : Polígono, 1972. p.93-99.

JOUSSIER, D.; CATROUX, G. Mise au point d'un milleau de culture pour le denombrement de Beauveria tenella dans le sols. Entomophaga, v.21, n.3, p.223-225, 1976.
LYNCH, J.M. Biotecnologia do solo. São Paulo : Manole, 1986. 210p.

LINGG, A.J.; DONALDSON, M.D. Biotic and abiotic factors affecting stability of Beauveria bassiana conidia in soil. Journal of Invertebrate Pathology, v.38, n.2, p.191-200, 1981.

MOREIRA, F.M.S.; SIQUEIRA, J.O. Microbiologia e bioquímica do solo. Lavras : UFLA, 2002. 626p.

OLIVEIRA, D.P. et al. Estudo comparativo da sobrevivência de Metarhizium anisopliae (Metsch.) Sorokin em diferentes tipos de solo. Revista Theobroma, v.11, n.4, p.233-239, 1981

OLIVEIRA, J.B. de. Pedologia aplicada. Jaboticabal : FUNEP, 2001. 414p.

PEREIRA, R.M. et al. Utilização de entomopatógenos no manejo integrado de pragas. In: ALVES, S.B. (ed.) Controle microbiano de insetos. 2.ed. Piracicaba : FEALQ, 1998. Cap.38, p.1097-1118.

PRADO, H. Solos do Brasil. 2.ed. Piracicaba : H. Prado, 2001. 220p

RATH, A.C. et al. The influence of abiotic factors on the distribution and abundance of Metarhizium anisopliae in Tasmanian pasture. Mycological Research, v.96, n.5, p.378384, 1992.

RATH, A.C. Ecology of entomopathogenic fungi in field soils. In: INTERNATIONAL COLLOQUIUM ON INVERTEBRATE PATHOLOGY AND MICROBIAL CONTROL, 8., 2002, Foz do Iguaçu, PR. Anais... Foz do Iguaçu : Society for Invertebrate Pathology, 2002. p. $65-71$

SHARAPOV, V.M.; KALVISH, T.K. Effect of soil fungistasis on zoopathogenic fungi. Mycopathology, v.85, n.2, p.121128,1984

SHIELDS, M.S. et al. Identification of a Penicillium urticae metabolite which inhibits Beauveria bassiana. Journal of Invertebrate Pathology, v.38, n.3, p.374-377, 1981.

SOSA-GOMEZ, D.R.; MOSCARDI, F. Effect of till and notill soybean cultivation of entomopathogenic fungi in the soil. Florida Entomologist, v.77, n.2, p.284-287, 1994.

STUDDERT, J.P.; KAYA, H.K. Water potential, temperature, and soil type on theation of eauveria bassiana soil colonies. Journal of Invertebrate Pathology, v. 56, n. 3, p. 380-3 86, 1990 . 